\section{Heart out of Darkness}

\section{Learning from End-of-life Care}

$\mathbf{T}$ his issue of the Journal features four articles that address issues related to the end of life. Together they are emblematic of the impressive breadth of work currently being done in this area. In recent years, end-of-life care has received increased interest on many fronts. The highly publicized and politicized debate over physician-assisted suicide has, among other things, emphasized the need for improved care for the dying. ${ }^{1,2}$ Professional organizations such as the Institute of Medicine, ${ }^{3}$ the American Medical Association, ${ }^{4}$ and the American College of Physicians ${ }^{5}$ have engaged in major efforts to improve the quality of endof-life care in the United States. Increasingly, physicians in many fields recognize the end of life to be a unique and important time for patients deserving of our best efforts. ${ }^{6-9}$ What is the potential effect of these combined efforts? To answer this question we start with end-of-life care's most obvious manifestation in medicine today.

The modern hospice movement began in 1967 with the founding of St. Christopher's Hospice by Dame Cicely Saunders. In part that movement was a response to medical care drifting away from its caring aspects (the relief of suffering) towards its curing aspects (the identification and treatment of disease) that paralleled the development of scientific medicine. ${ }^{10}$ Since then the reality of medicine has been shaped more by its curing, technological aspects than by its caring, humanistic ones. ${ }^{11}$ This imbalance has created a tension both for patients and for those who entered the health professions because they wanted to care for people as well as cure them. ${ }^{12}$ We suggest that the increased efforts in clinical work, scholarship, public policy, and education in end-of-life care are a response to this tension. As these efforts continue, there will be opportunities to integrate lessons learned in end-of-life work into other areas of medical care. The four articles presented here contribute to this task and in so doing draw on a variety of disciplines. By using expertise outside traditional medicine, each article in its own way challenges us to think differently and creatively about the issues they examine.

From the field of doctor-patient communication, Breen et al. ${ }^{13}$ present a carefully done qualitative study of conflict associated with decisions to limit life-sustaining treatment in 102 patients treated in 6 intensive care units at Duke University Medical Center. The authors show that conflict occurs frequently (in $78 \%$ of cases in this study) and make the point that conflict can be constructive, noting that "a period of dissent may be necessary for both sides to appreciate the other's perspective and to find accommoda- tion." While it may be a necessary process, it is worth speculating about the sources of this dissent. For medical providers, and even more for patients' families, discussions about limiting life-sustaining treatment invoke two 'worst fears.' Continuing care risks forcing a needlessly prolonged death 'hooked up to tubes and machines' while withdrawing care risks abandoning the patient at their time of greatest helplessness. ${ }^{14}$ The authors suggest several strategies for navigating these difficult situations that could be applied in any patient care setting where conflict occurs. For many, intensive care units remain the most vivid symbol of the scientific approach to death. This study points out that even in the most technologically dominated settings, opportunities exist to become more caring, humanistic and complete physicians.

Utilizing expertise in the fields of law, ethics, and public policy, Whitney et al. ${ }^{15}$ surveyed a nationwide sample of physicians about their views regarding the legalization of physician-assisted suicide, and compared these views with those of members of the AMA's House of Delegates. Views among U.S. physicians varied widely, with $45 \%$ believing physician-assisted suicide should be legal, $34 \%$ believing it should be illegal, and $22 \%$ undecided. In contrast, $61 \%$ of the AMA Delegates were opposed to the legalization of physician-assisted suicide, a position consistent with the AMA's public position on this issue. ${ }^{16}$ The authors note that respondents' political views and certain religious factors were strongly associated with opposition to legalization of physician-assisted suicide. Of interest, a majority in both groups favored no legislation with respect to physician-assisted suicide, preferring to have this issue handled in the context of the doctor-patient relationship. An obvious concern that follows from these findings is the extent to which a physician's personal beliefs might influence decisions (in either direction) about physician-assisted suicide for individual patients. This paper is an important contribution to the growing literature on physician-assisted suicide. What is particularly compelling about this debate is that deep caring for patients and physicians is clearly motivating the parties on both sides. ${ }^{1,2}$ The request for physician-assisted suicide has forced physicians to reckon with a group of patients who feel that medicine has nothing better to offer them. This reckoning has spurred physicians to develop new ways of understanding patients' perspectives, ${ }^{17}$ communicating, ${ }^{18}$ and addressing pain and suffering, ${ }^{19}$ lessons that could be helpful to all patients. 
Drawing on the fields of theatre and literary criticism Sulmasy ${ }^{20}$ offers a remarkable commentary on the Pulitzer Prize-winning Play, $W$; , by Margaret Edson. He invites us to look beyond the boundaries of end-of-life care and even medicine itself to see our patients and ourselves as human beings, as persons first and last. He suggests that we recognize the broader themes that flow from the play and bind us to each other: forgiveness, relationship, and dignity. He challenges us to forgive ourselves and allow ourselves to be forgiven, to transcend the difficult reality of death to become the 'persons of reconciling love' our patients need us to be.

But is this enough? Becoming better persons and in turn better doctors, while important, will not overcome a hostile or even inadequate system of care: a bad system can thwart even the best of doctors. We need fundamental change and improvement at a systems level in order to care adequately for our patients and to attend their suffering. Such change is facilitated by a dose of humanity: caring enough to notice the violation of patient dignity and the compromise to relationship and continuity, and caring enough to think creatively about how to fix these problems. Perhaps this is one response to Jason's (the oncology fellow in $W$; $t$ ) "salvation anxiety": pressing on with courage and creativity in the face of uncertainty with the hope of making things better for our patients, and perhaps ourselves.

Addressing the problem of a flawed system, Lynn and Forlini $^{21}$ present a thought-provoking argument for redefining the way that we conceptualize care for patients at the end of life. Drawing on expertise in health-care policy and finance, they argue that our current health-care system is not well suited to care for many patients at the end of their lives who are not hospice-eligible. Current structures and financing of care are not congruent with the experiences of patients with "serious and complex illness," as anyone who has struggled to care for such patients can testify. This paper points out that policies and systems of care that are not responsive to the needs of individual patients (and the providers attempting to care for them) fail to the extent that this is the case. In this paper in particular, lessons learned from caring for dying patients show the potential to inform our care of ever more inclusive categories of patients. In the same way that the creation of hospice was the first step towards improving care for terminally ill patients, this paper points out the crucial next step: improving the systems and structures of care for patients who are very ill and may die, but not in a predictable 6-month time frame.

It's been almost 20 years since Eric Cassell's classic article, "The Nature of Suffering and the Goals of Medicine," gave voice to the medical profession's need to balance caring for suffering patients with the cure of disease. ${ }^{22}$ As he wrote then: “. . the relief of suffering and the cure of disease must be seen as twin obligations of a medical profession that is truly dedicated to the care of the sick. Physicians' failure to understand the nature of suffering can result in medical intervention that (though technically adequate) not only fails to relieve suffering but becomes a source of suffering itself." We propose that these twin obligations are being best met in the myriad efforts to care for patients at the end of life. More importantly, as stated by Lynn and Forlini, patients who are imminently dying are not the only patients who need both obligations met. Every patient deserves to have both medical care and human caring. Perhaps because of the mystery of death, perhaps because we feel inadequate in situations where we cannot cure, for whatever reasons, physicians increasingly recognize the end of patients' lives as a sacred time deserving our best and most human care. We should acknowledge that the rest of patients' lives deserve this same attention and this same care. To this end work done in end-of-life care represents the leading edge of a wedge that is reintroducing human caring into all medical care. In Holy Sonnet X (Gardner edition VI), John Donne states: "Death be not proud, though some have called thee mighty and dreadful, for thou art not so." Not only is death not proud, it is not more sacred than life. Lessons learned in caring for patients at the end of their lives can teach us much about caring for all patients. ERIK Fromme, MD and Joseph Carrese, MD, MPH, Johns Hopkins Bayview Medical Center, Baltimore, Md.

The authors would like to thank Eric Cassell, MD for inspiration and guidance in developing the central theme of this essay.

Dr. Carrese is a Robert Wood Johnson Generalist Physician Faculty Scholar, and a core faculty member of the Johns Hopkins University Bioethics Institute.

\section{REFERENCES}

1. Angell M. The Supreme Court and physician-assisted suicide-the ultimate right. N Engl J Med. 1997;336:50-3.

2. Foley KM. Competent care for the dying instead of physicianassisted suicide. N Engl J Med. 1997;336:54-8.

3. Fields MJ, Casell CK, eds. Approaching Death: Improving Care at the End of Life. Washington D.C.: National Academy Press; 1997.

4. The EPEC Project Team. EPEC: Education for physicians in end of life care. The American Medical Association. October 1999.

5. Quill TE, Byock IR. Responding to intractable terminal suffering: the role of terminal sedation and voluntary refusal of food and fluids. ACP-ASIM End-of-Life Care Consensus Panel. American College of Physicians-American Society of Internal Medicine. Ann Intern Med. 2000;132:408-14.

6. Goldstein B, Merkens M. End-of-life in the pediatric intensive care unit: seeking the family's decision of when and how, not if. Crit Care Med. 2000;28:3122-3.

7. Fallon M. Molecular genetics and palliative medicine: what is the link? Palliat Med. 2000;14:255-6.

8. Lovel T. Palliative care and head and neck cancer. Br J Oral \& Maxillofacial Surg. 2000;38:253-4.

9. Schmidt T. Futility-futilis-the leaky vessel. Ann Emerg Med. 2000;35:615-7.

10. Saunders C. Foreward. In: Doyle D, Hanks GWC, MacDonald N, eds. Oxford Textbook of Palliative Medicine, 2nd ed. New York: Oxford University Press; 1998:p. v-ix.

11. Engel GL. The need for a new medical model: a challenge for biomedicine. Science. 1977;196:129-36. 
12. Engel GL. Physician scientists and scientific physicians. Resolving the humanism science dichotomy. Am J Med. 1987;82: 107-11.

13. Breen CM, Abernethy AP, Abbott KH, Tulsky JA. Conflict associated with decisions to limit life-sustaining treatment in intensive care units. J Gen Intern Med. 2001;16:283-9.

14. Fields MJ, Casell CK, eds. Approaching Death: Improving Care at the End of Life. Washington DC: National Academy Press; 1997:15.

15. Whitney SN, Brown BW, Brody H, Alcser KH, Bachman JG, Greely JD. Views of United States physicians and members of the American Medical Association House of Delegates on physicianassisted suicide. J Gen Intern Med. 2001;16:290-6.

16. Council on Ethical and Judicial Affairs, American Medical Association. Decisions near the end of life. JAMA. 1992;267: 2229-33.
17. Tolle SW, Tilden VP, Nelson CA, Dunn PM. A prospective study of the efficacy of the physician order form for life-sustaining treatment. J Am Geriatr Soc. 1998;46:1097-102.

18. Block SD, Billings JA. Patient requests to hasten death. Evaluation and management in terminal care. Arch Intern Med. 1994;154:2039-47.

19. Foley KM. Pain, physician-assisted suicide and euthanasia. Pain Forum. 1995;4:163-78.

20. Sulmasy DP. At wit's end: forgiveness, dignity, and the care of the dying. J Gen Intern Med. 2001;16:335-8.

21. Lynn J, Forlini JH. "Serious and complex illness" in quality improvement and policy reform for end-of-life care. J Gen Intern Med. 2001;16:315-9.

22. Cassell EJ. The nature of suffering and the goals of medicine. N Engl. J Med. 1982;306:639-43. 